\title{
Mechanical Properties of Dissimilar A356/SAPH440 Lap Joints by the Friction Stir Spot Welding and Self-Piercing Riveting
}

\author{
Han Sur Bang, ${ }^{a, 1}$ W. R. Lee, ${ }^{b}$ S. M. Hong, ${ }^{b}$ S. Y. Lee, ${ }^{b}$ J. H. Song, ${ }^{c}$ J. M. Kim, ${ }^{d}$ and \\ Hi Seon Bang ${ }^{a}$
}

\author{
${ }^{a}$ Department of Welding and Joining Science Engineering, Chosun University, Republic of Korea \\ ${ }^{\mathrm{b}}$ Department of Welding and Joining Science Engineering, Graduate School, Chosun University, \\ Republic of Korea \\ ${ }^{c}$ Korea Automotive Technology Institute, Republic of Korea \\ d Department of Mechanical Convergence Engineering, Jeonnam Provincial College, Republic of \\ Korea \\ ${ }^{1}$ banghs@chsoun.ac.kr
}

Aluminum alloy A356-T6 and automotive steel sheet SAPH440 were joined using friction stir spot welding and self-piercing riveting. The maximum tensile shear strength values in weld joints were approximately $3.5 \mathrm{kN}$ at a rotation speed of $500 \mathrm{rpm}$ and plunge depth of $1.0 \mathrm{~mm}$. It was confirmed that the intermetallic compound layer of weld joints below $9.23 \mu \mathrm{m}$ did not exceed the permissible thickness $10 \mu \mathrm{m}$ of Al-Fe joints. The self-piercing riveting joints exhibited maximum tensile- shear strength of $7.9 \mathrm{kN}$, which was higher than that of the weld joints. However, during the riveting process, cracking appeared in the joint on the aluminum side, which was caused by lack of ductility of cast aluminum. In addition, it was observed that the cracks on the aluminum side were getting larger, as the radius of the lower mold increased.

Keywords: dissimilar material, friction stir spot welding, self-piercing rivet, intermetallic compound, tensile-shear strength.

Introduction. As fuel-related regulations are being strengthened in the automobile industry, the method of reducing the weight of the vehicle has been challenged by applying a new joining process for conventional steel to a lightweight material such as non-ferrous metal. However, welding or joining for dissimilar materials of aluminum alloy and steel is difficult to obtain the adequate joint strength due to the difference of physical and mechanical properties. Therefore, new welding and mechanical bonding methods into dissimilar materials of aluminum alloy and steel are required.

One of the solid state welding processes, friction stir spot welding (FSSW) is considered as a promising method to join dissimilar materials using plastic deformation caused by the low heat input, rotational force and pressure of the tool. This can suppress formation of weld defects such as blow hole, cracking, and brittle intermetallic compounds (IMC) resulting from conventional fusion welding, which deteriorate the mechanical properties of the joints [1-5]. This can suppress formation of weld defects including cracking, blow hole, and brittle IMC that can degrade the joint mechanical properties in conventional fusion welding [1-5]. Conspicuously, minimizing the IMC layer is required to guarantee the joints reliability of the dissimilar materials [6]. Yeon et al. [7] and Kim et al. [8] reported that adopting FSSW to join dissimilar materials leads acceptable lap joints which produce decent strength. Self-piercing riveting (SPR) is a mechanical bonding method using rivets [9], in which drilling or alignment process between the material and the rivet machine were not required unlike conventional rivets.

Therefore, this study intended to carry out the lap joining of aluminum alloy (A356) and automotive steel (SAPH440) sheets, using FSSW and SPR methods [10, 11]. Moreover, 
joint properties of aluminum alloy (A356) and automotive steel (SAPH440) were analyzed in the views of mechanical characteristics and of metallurgical characteristics [12-15].

1. Experimental Details. Aluminum alloy (A356) and automotive steel (SAPH440) sheets, were adopted as dissimilar materials in this study. The chemical composition and mechanical properties of materials are shown in Table 1. Each size of the dissimilar material specimen that was adopted in this study was $150 \mathrm{~mm}$ (length $L) \times 50 \mathrm{~mm}$ (width $W) \times 3 \mathrm{~mm}$ (thickness $t$ ) of A356-T6 and $150 \mathrm{~mm}(L) \times 50 \mathrm{~mm}(W) \times 2 \mathrm{~mm}(t)$ of SAPH440. Aluminum alloy plate was set on the top side of the steel plate. The two plates were overlapped for $50 \mathrm{~mm}$ as shown in Fig. 1.

$\mathrm{T}$ a $\mathrm{b} 1 \mathrm{e} 1$

Chemical Composition and Mechanical Properties of A356-T6 and SAPH440

\begin{tabular}{|c|c|c|c|c|c|c|c|c|}
\hline Material & \multicolumn{8}{|c|}{ Chemical composition (wt.\%) } \\
\hline \multirow[t]{2}{*}{ A356-T6 } & $\mathrm{Mg}$ & $\mathrm{Mn}$ & $\mathrm{Fe}$ & $\mathrm{Zn}$ & $\mathrm{Si}$ & $\mathrm{Cu}$ & $\mathrm{Ti}$ & $\mathrm{Al}$ \\
\hline & 0.45 & 0.10 & 0.20 & 0.10 & 7.5 & 0.20 & 0.20 & Bal. \\
\hline \multirow[t]{4}{*}{ SAPH440 } & $\mathrm{C}$ & $\mathrm{Si}$ & $\mathrm{Mn}$ & $\mathrm{P}$ & $\mathrm{S}$ & Al & & \\
\hline & 0.074 & 0.014 & 1.254 & 0.012 & 0.004 & 0.028 & & \\
\hline & \multicolumn{8}{|c|}{ Mechanical properties } \\
\hline & \multicolumn{2}{|c|}{ UTS (MPa) } & \multicolumn{3}{|c|}{ YS (MPa) } & \multicolumn{3}{|c|}{ EL (\%) } \\
\hline A356-T6 & \multicolumn{2}{|c|}{230.0} & \multicolumn{3}{|c|}{185.0} & \multicolumn{3}{|c|}{2} \\
\hline SAPH440 & \multicolumn{2}{|c|}{447.2} & \multicolumn{3}{|c|}{332.5} & \multicolumn{3}{|c|}{37} \\
\hline
\end{tabular}

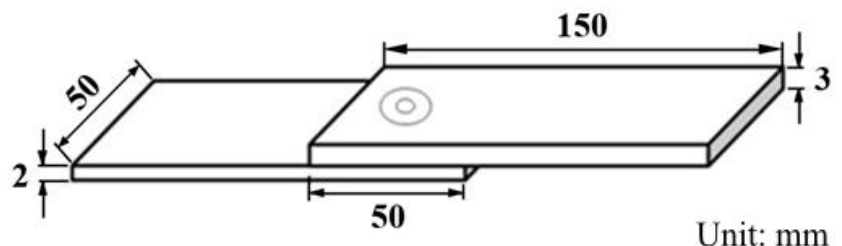

Fig. 1. Configuration of specimen.

1.1. FSSW. The friction stir spot welding conditions were as follows: $300-500 \mathrm{rpm}$ of a tool rotation speed, $0.2-1.2 \mathrm{~mm}$ of a tool plunge depth, $1.0 \mathrm{~mm} / \mathrm{s}$ of a tool insertion speed, and $15 \mathrm{~s}$ of dwell time. The friction stir spot welding was performed under these 15 conditions as shown in Table 2.

$\mathrm{T}$ a b 1 e 2

Welding Conditions for FSSW

\begin{tabular}{|c|c|c|}
\hline Case & Rotation speed $(\mathrm{rpm})$ & Plunge depth $(\mathrm{mm})$ \\
\hline $1-5$ & 300 & $0.2,0.5,0.7,1.0,1.2$ \\
\hline $6-10$ & 400 & $0.2,0.5,0.7,1.0,1.2$ \\
\hline $11-15$ & 500 & $0.2,0.5,0.7,1.0,1.2$ \\
\hline
\end{tabular}

The WC-12\% Co welding tool with smooth frustum type and tilted $3^{\circ}$ forward from the vertical was used in this study. The welding tool is composed of a shoulder with 

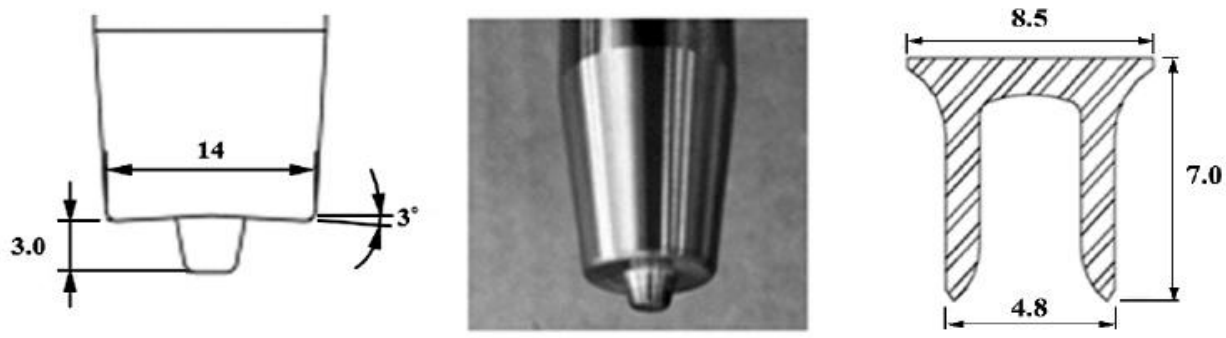

Fig. 2. Tool and rivet shape and details.

diameter of $14 \mathrm{~mm}$, and pin with length of $3.0 \mathrm{~mm}$, upper the diameter of $6.0 \mathrm{~mm}$, and the bottom diameter of $4.0 \mathrm{~mm}$ (see Fig. 2).

The influences of rotation tool speed and of tool plunge depth on the FSSW were investigated through the joint formation, mechanical and metallurgical characteristics analyses.

1.2. SPR. The self-piercing riveting joining conditions were as follows: a punch speed of $0.5 \mathrm{~mm} / \mathrm{s}$, upper diameter of rivet of $8.5 \mathrm{~mm}$, a depth of $7.0 \mathrm{~mm}$, a lower diameter of $4.8 \mathrm{~mm}$, a lower mold depth of 1.1-1.4 mm, a lower mold radius of 5.0-7.0 mm. The shape of a rivet was fixed, but depth, diameter of the lower mold was varied. The lower mold depth and radius were selected from the result of the pre-test. Four conditions for the lower mold are shown in Table 3.

T a b 1 e 3

\section{Joining Conditions for SPR}

\begin{tabular}{|c|c|c|}
\hline Case & $\begin{array}{c}\text { Lower mold depth (die depth } H), \\
\mathrm{mm}\end{array}$ & $\begin{array}{c}\text { Lower mold radius (die radius } R), \\
\mathrm{mm}\end{array}$ \\
\hline 1 & 1.2 & 5.0 \\
\hline 2 & 1.1 & 6.0 \\
\hline 3 & 1.2 & 7.0 \\
\hline 4 & 1.4 & 7.0 \\
\hline
\end{tabular}

In order to evaluate the mechanical properties of the SPR joints, tensile-shear strength test and Vickers hardness test were carried out. Following KS B 0851 and ASTM E92-82 standards, the tensile-shear strength test and hardness test were performed respectively. Along with every $0.5 \mathrm{~mm}$ of cross section of workpiece, the Vickers hardness profiles were measured within the condition of $0.5 \mathrm{kgf}$ load and $10 \mathrm{~s}$ dwell time. The metallurgical characteristics were clarified through the SEM analysis.

\section{Results and Discussion.}

\subsection{FSSW.}

2.1.1. Joint Characteristics of the FSSW Joints. The attaining sound joints, FSSW experiments were performed in 15 cases of welding conditions. In the range of $0.2-1.2 \mathrm{~mm}$ tool plunge depths at 300-500 rpm tool rotation speeds were observed. The characteristics of the cross section of the joints are investigated, in view of three main factors including weldability, the size of the hook and the effective sheet thickness, which have influence on the mechanical characteristics of the joints. Figure 3 shows the bead profiles of the FSSW joints in various rotation speeds and plunge depths. As shown in Fig. 3a, the lap joints appeared as sound shape without any defect on the surface, and the burr came out in all 


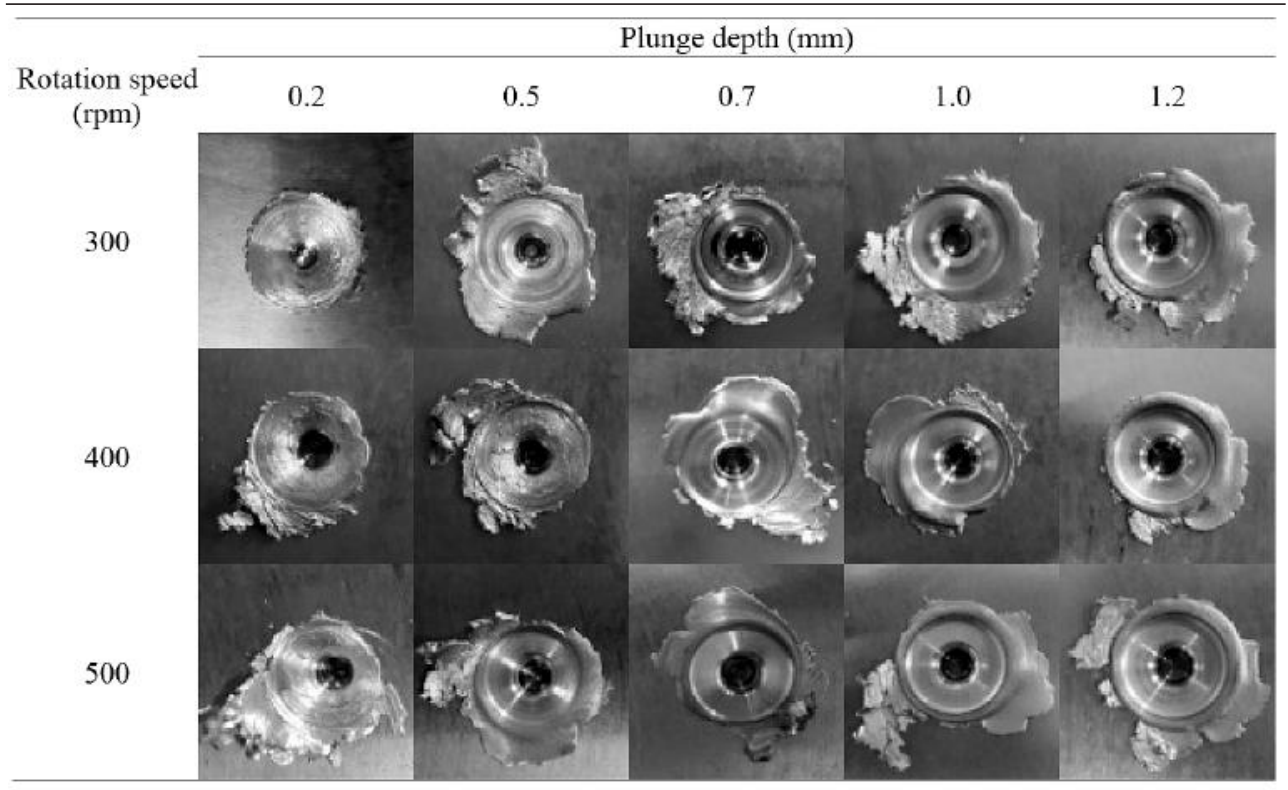

$\mathrm{a}$

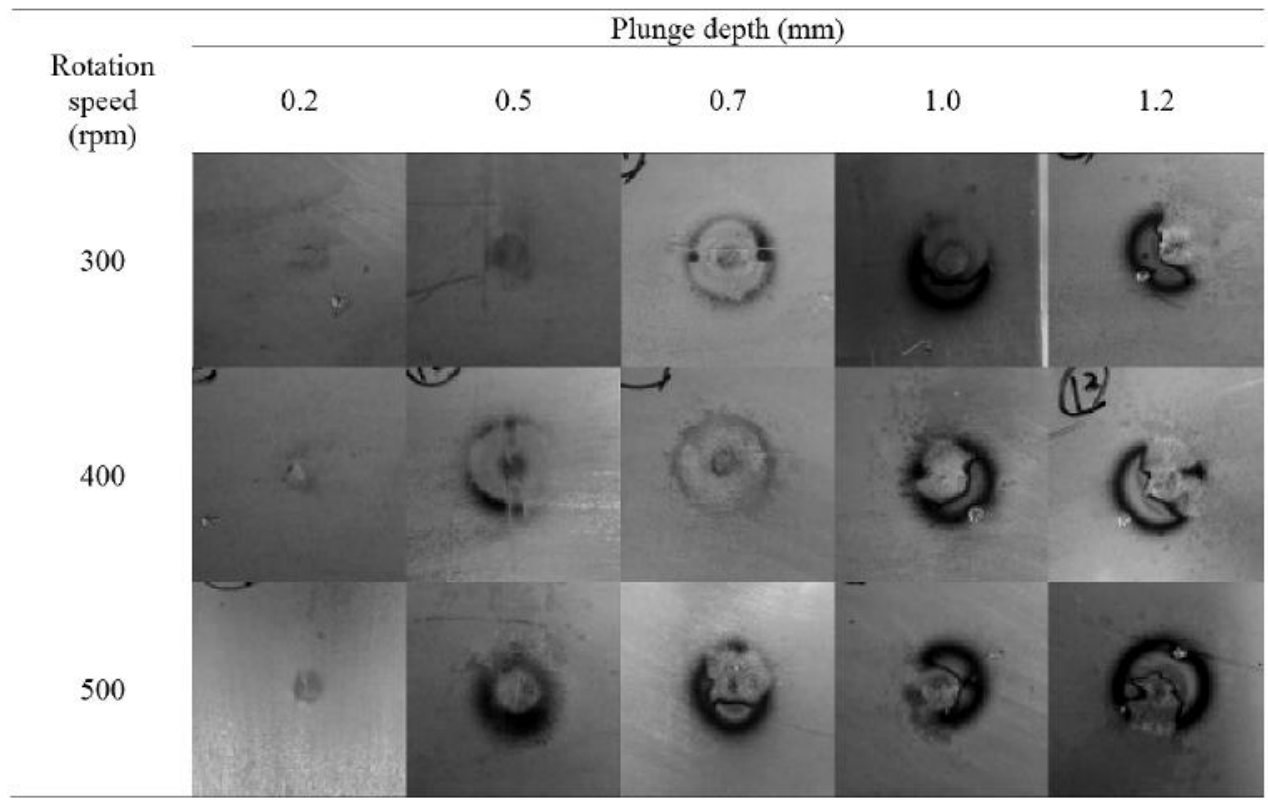

b

Fig. 3. The bead profiles of the FSSW joints with rotation speed and plunge depth: top (a) and back (b) bead profiles.

conditions except in $0.2 \mathrm{~mm}$ plunge depth at rotation speed of $300 \mathrm{rpm}$. In the plunge depths of 0.2 and $0.5 \mathrm{~mm}$, there was little smear in the back bead, which was expected to be unjoined due to the lack of stirring between the upper and lower materials. The deeper plunge depth resulted more smear in the back bead as shown in Fig. $3 \mathrm{~b}$.

The cross sectional view of the joints from Fig. 4, the interface of joints appeared as sound shapes in all conditions ranging 300-500 rpm at plunge depth of $0.7-1.2 \mathrm{~mm}$. During the process, however, the formation of hooks occurred in the upper side of A356-T6 


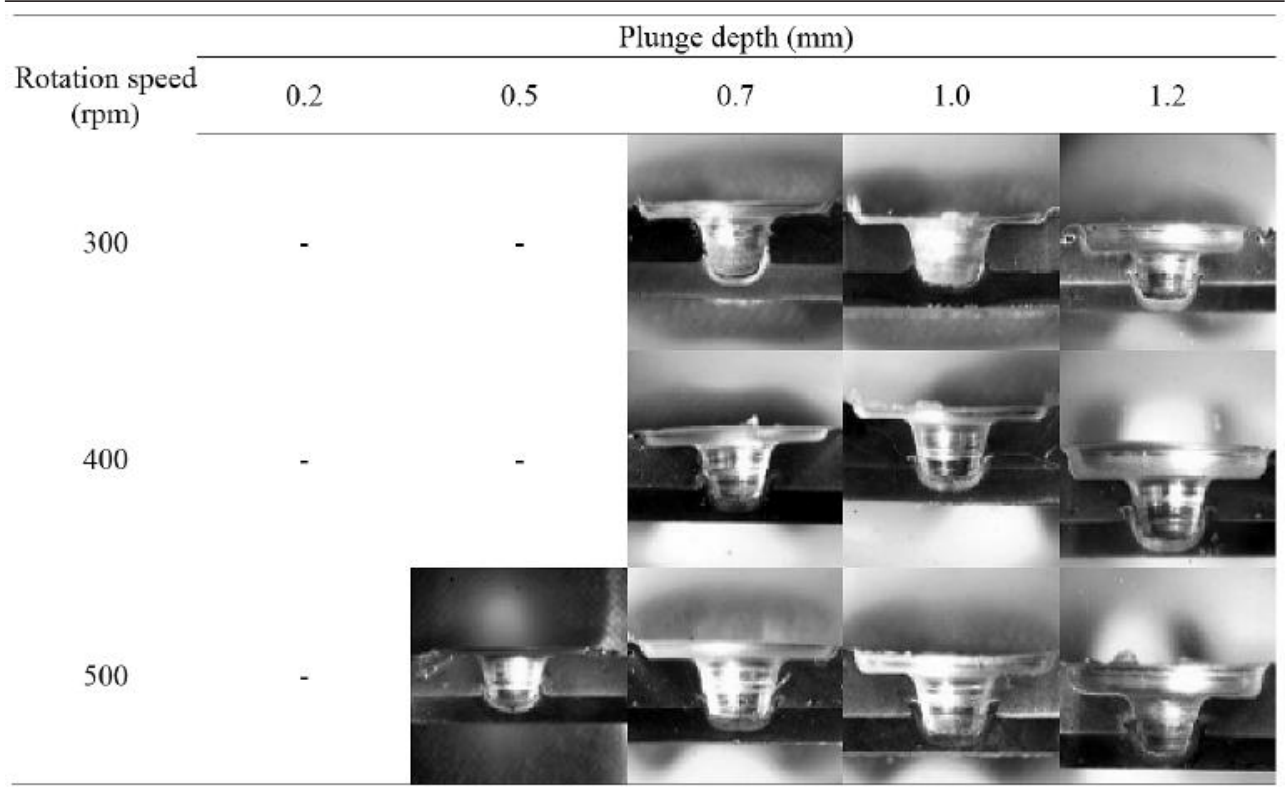

Fig. 4. The cross section view of the FSSW joints with plunge depth and rotation speed.

including both advancing and retreating sides, and also it appeared in the left- and right-hand sides of the pin of the lower joint side. The mechanism of hook formation is as following: Through a tool down force and plastic flow, the bottom side of SAPH440 permeates into the top side of A356-T6. When rotation speed increased, the hook size did not become larger considerably, notably, with increasing plunge depth, the hook tended to increase. When the plunge depths were $0.2-0.5 \mathrm{~mm}$, the lap-joints became imperfect because of inadequate plastic flow and deformation between A356-T6 in upper side and SAPH440 in lower side. It was thought that this was because the pin simply touched the upper direction surface of SAPH440, caused by the lack of stirring effect in the time of the process. Over than $0.7 \mathrm{~mm}$ of plunge depth, perfect lap-joints appeared in the interface of the joints due to enough plastic flow effect in the upper and lower plates. As shown in Fig. 4, the decreased thickness of upper surface of A356-T6 was observed with increasing tool plunge depth. Notably, when the plunge depth became deeper than $1.0 \mathrm{~mm}$, the effective sheet thickness showed more decrease. These results indicated that the effective sheet thickness satisfied the allowed value, below $10 \%$ of the sheet thickness as are the requirements of the resistance spot welding.

2.1.2. The Tensile-Shear Strength of FSSW Joints. Figure 5 represents the tensile-shear strength of the of the joints based on the welding condition of $0.2-1.2 \mathrm{~mm}$ tool plunge depths with 300-500 rpm tool rotation speed; the correlations between the tensile-shear strength of FSSW joints and rotation speed is shown at (a), and it between the tensile-shear strength of joints and plunge depth is at (b). To estimate the tensile-shear strength of the joints, the joint formation, the fracture pattern and the reduction of the effective thickness of the upper side of the A356-T6 were considered as a main view. Within 300-500 rpm of rotation speed, the strength tended to reach higher point when the rotation speed increase. The approximate maximum tensile-shear strength of joints was $3.5 \mathrm{kN}$ at $500 \mathrm{rpm}$ of rotation speed. While the strength was higher in the plunge depth range of 0.2 to $0.7 \mathrm{~mm}$, the strength started to be decreased when the plunge depth was deeper than $1.0 \mathrm{~mm}$. When the tool plunge depth was $1.0 \mathrm{~mm}, 3.5 \mathrm{kN}$ of the maximum tensile-shear strength of joints was acquired. In terms of the fracture patterns from the tensile-shear strength test, interface fracture was generated in joints when the plunge depth was shallower than $0.7 \mathrm{~mm}$. This 


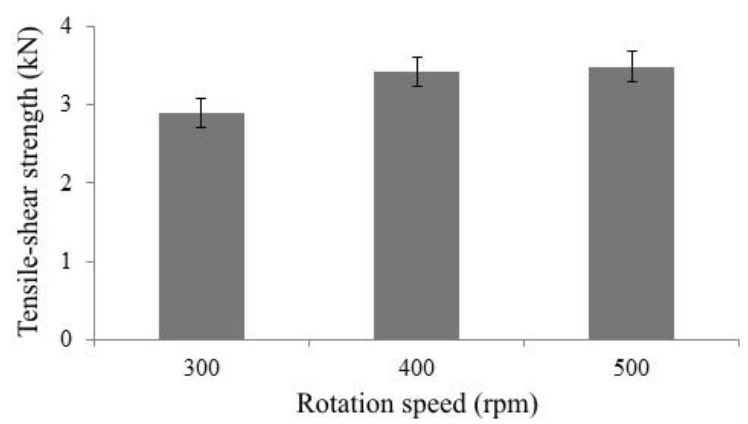

a

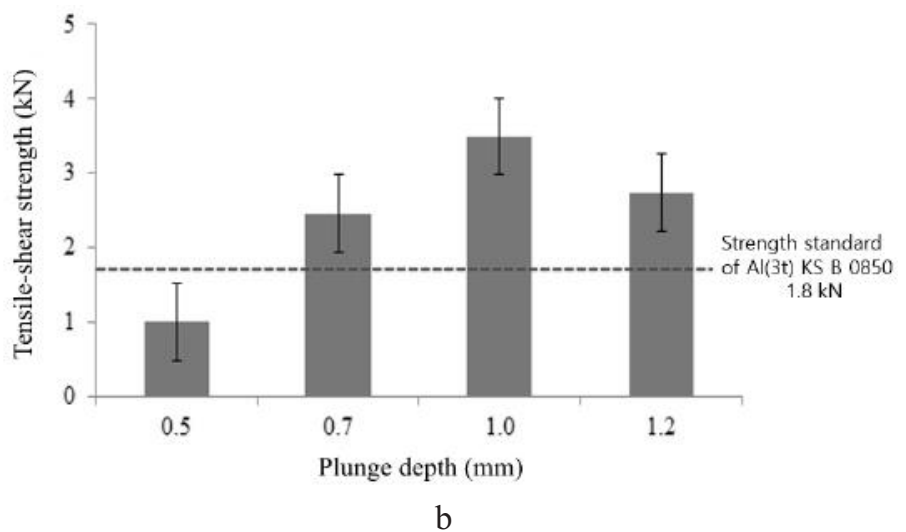

Fig. 5. The tensile-shear strength of FSSW joints with rotation speed (a) and plunge depth (b).

was attributed to interface of the joints with a non-welded zone caused by insufficient stirring effect. However, over $1.0 \mathrm{~mm}$ of tool plunge depth, happened with the interface of the joints without any non-welded zone on account of ample plastic flow effect from the materials in upper and lower side.

At a tool plunge depth of $1.0 \mathrm{~mm}$, interface of the lap-joint showed not only fully welded state but also slightly reduced effective sheet thickness of the joints and the maximum tensile-shear strength. The tests for tensile-shear strength and hardness were performed respectively according to KS B 0851 and ASTM E92-82 standards. All conditions except for the plunge depth of $0.5 \mathrm{~mm}$, it is satisfied KS B 0850 standard which is tensile-shear strength of over $1.8 \mathrm{kN}$ of $3 \mathrm{~mm}$ thickness aluminum joints.

2.1.3. The Hardness Distribution of FSSW Joints. Figure 6 shows the hardness distribution of the FSSW joints; (a) is the upper - A356-T6 side, (b) is the bottom SAPH440 side. The hardness tests were measured at different plunge depths and the rotation speed of $500 \mathrm{rpm}$. As a result of the test, the maximum hardness value of $228 \mathrm{HV}$ was observed at the plunge depth of $1.2 \mathrm{~mm}$. This was the higher value compared to A356-T6 hardness value of $50 \mathrm{HV}$; on the other hand, maximum hardness value of $275 \mathrm{HV}$ on SAPH440 steel side was observed. This was 115 HV higher than the SAPH440 base metal. It was considered that the hardness value was increased in both aluminum and steel due to dynamic re-crystallization originated from the heat and the mechanical force as the plunge depth and tool rotation speed increased.

2.1.4. Microstructural Characteristics of FSSW Joints. The microstructures of the specimens under the welding condition of $500 \mathrm{rpm}$ with $1.0 \mathrm{~mm}$ of plunge depth indicated the highest tensile-shear strength among the specimens. Figure 7 presents the microstructure of the stir zone (SZ), thermomechanically affected zone (TMAZ), heat-affected 


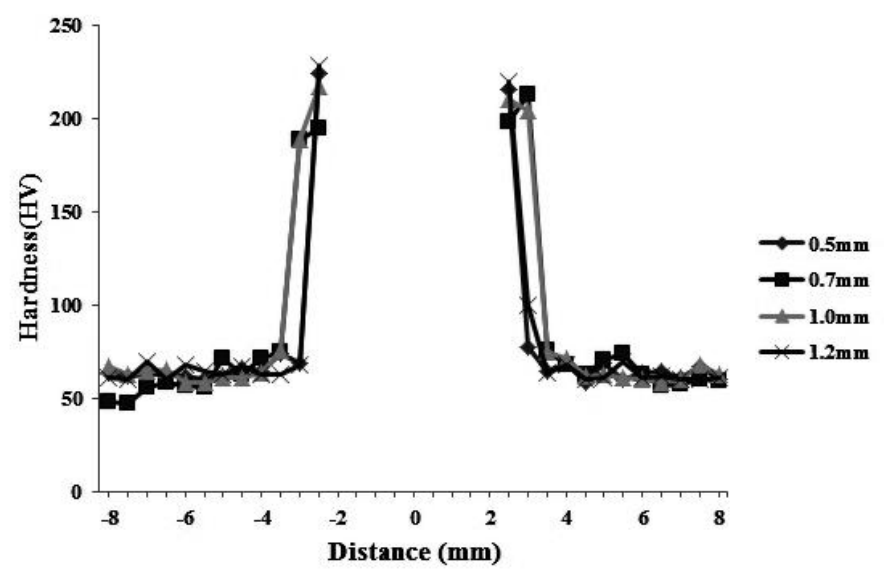

a

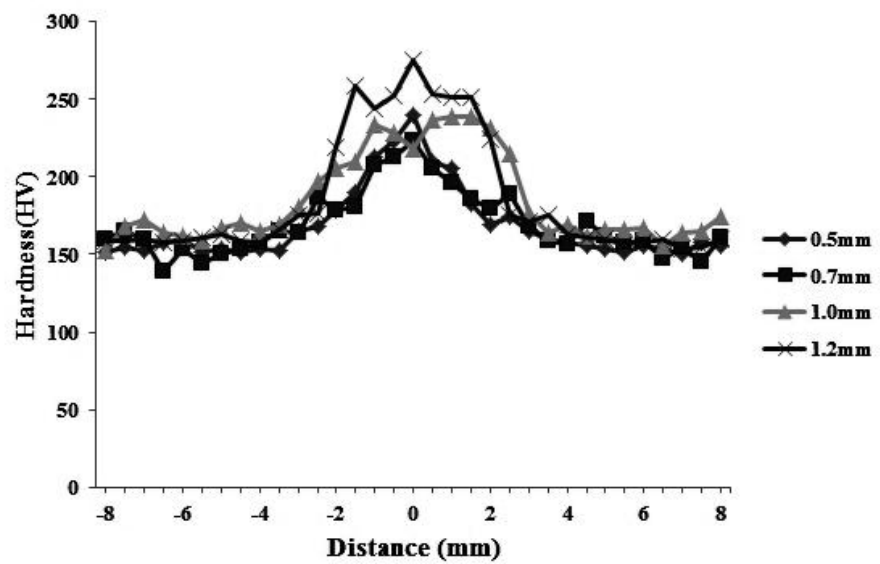

b

Fig. 6. The hardness distributions of FSSW joints with plunge depth.

zone (HAZ), and base metal (BM) of a joint individually, and the plunge depth for the FSSW joint is $1.0 \mathrm{~mm}$ with $500 \mathrm{rpm}$ of rotation speed; (a)-(c) gives the microstructure of A356-T6 top side, and (d)-(f) shows the bottom side of SAPH440. Microstructures of (b) and (c) which is the SZ and TMAZ of A356-T6, were finer because of the dynamic re-crystallization from the heat and mechanical force. Although the HAZ has the slightly coarser microstructure, its structure is practically akin to the microstructure of base metal. In addition, the IMC layer was observed in the condition of $0.7-1.2 \mathrm{~mm}$ plunge depth. As shown in Fig. 8, when the plunge depth is $0.7,1.0$, and $1.2 \mathrm{~mm}$, the IMC thickness is maximum 5.93, 8.59, and $9.23 \mu \mathrm{m}$, respectively. It was observed that the IMC thickness increased as the plunge depth increased. This was caused by increase of the mechanical force and frictional heat as the plunge depth increases. The plunge depth of 0.7 to $1.2 \mathrm{~mm}$ satisfied the IMC thickness within $10 \mu \mathrm{m}$, required for the dissimilar material welding.

From 0.7 to $1.2 \mathrm{~mm}$ of plunge depth condition, in addition, the IMC layer was observed. As shown in Fig. 7, when the plunge depth is $0.7,1.0$, and $1.2 \mathrm{~mm}$, the IMC thickness is maximum 5.93, 8.59, and $9.23 \mu \mathrm{m}$, each. It was observed that the IMC thickness increased when the plunge depth became deeper. This was caused by pressing force and frictional heat as the plunge depth increases. The plunge depth of 0.7 to $1.2 \mathrm{~mm}$ satisfied the IMC thickness within $10 \mu \mathrm{m}$, required for the dissimilar material welding. 
Mechanical Properties of Dissimilar A356/SAPH440 Lap Joints ...

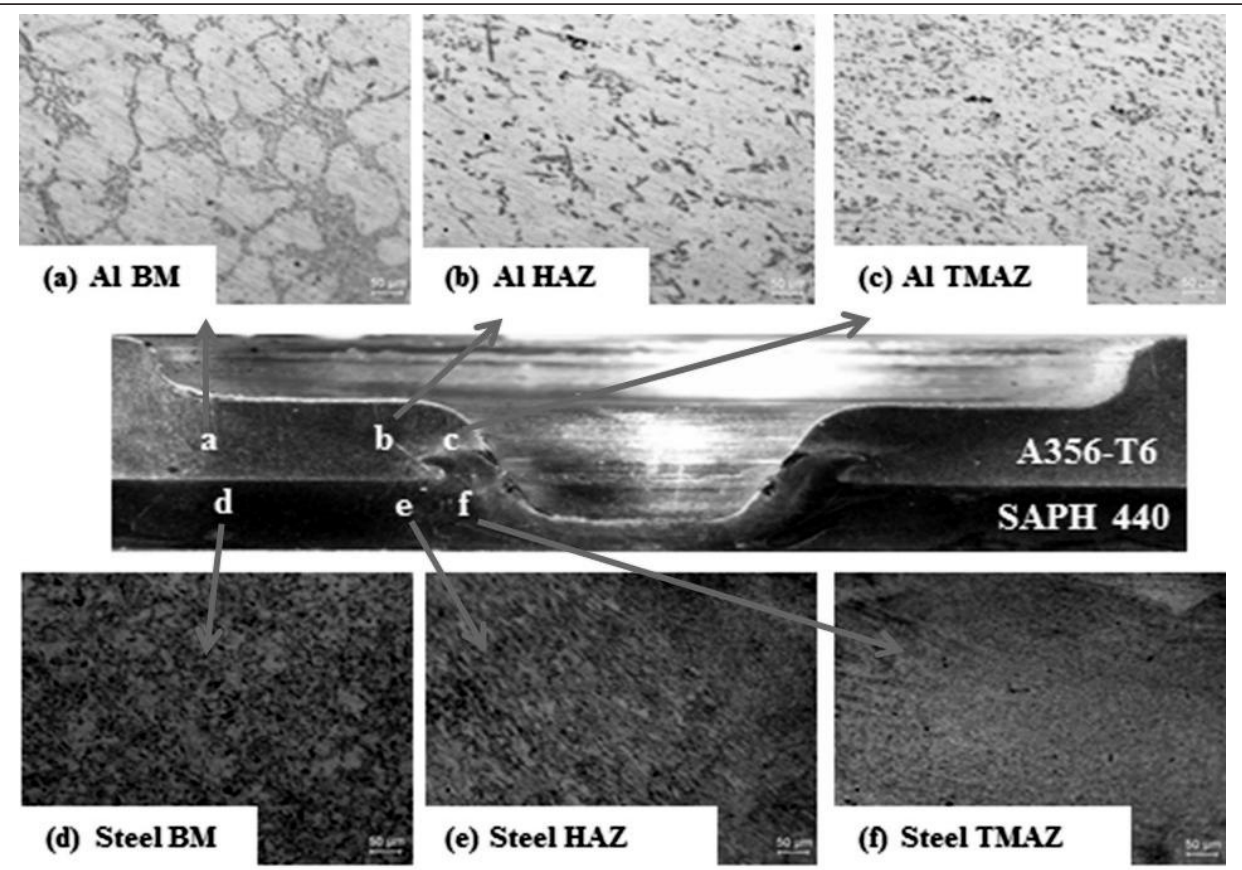

Fig. 7. Microstructure of the FSSW joints.

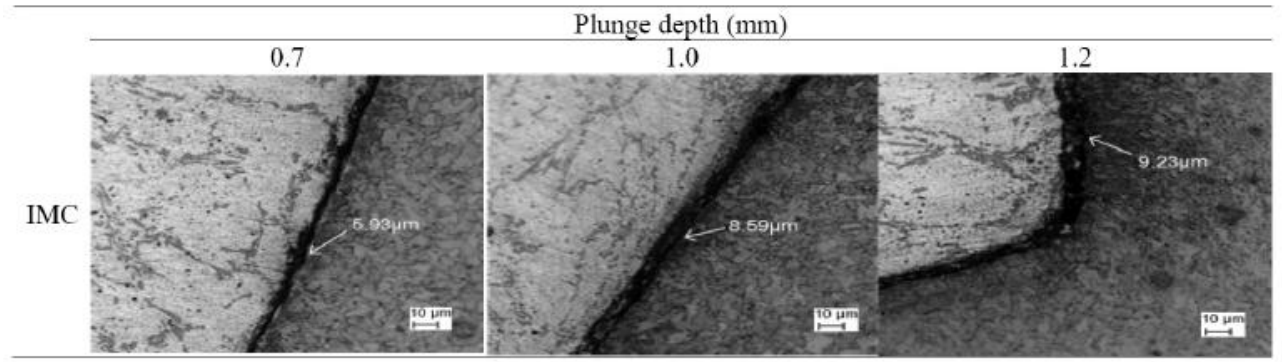

Fig. 8. Thickness of IMC in FSSW joints with plunge depth.

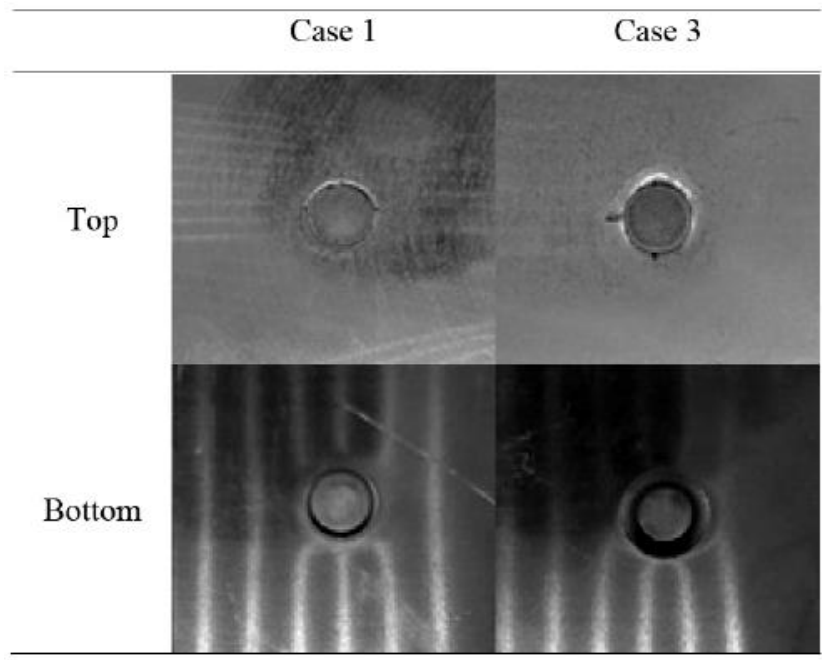

Fig. 9. Configuration of specimen of SPR joints. 


\subsection{SPR Joints.}

2.2.1. Joint Characteristic of SPR Joints. For obtaining sound joints, SPR experiments were performed in 4 cases of joining conditions. The lower mold depth of of 1.1-1.4 mm and radius of of 5.0-7.0 mm were observed. With the view of defects, the characteristics of the cross sections in SPR joints were investigated. Figures 9 and 10 show that the highest strain distance ratio of rivet was in cases 1 and 3 and the cross section of SPR joints, respectively.

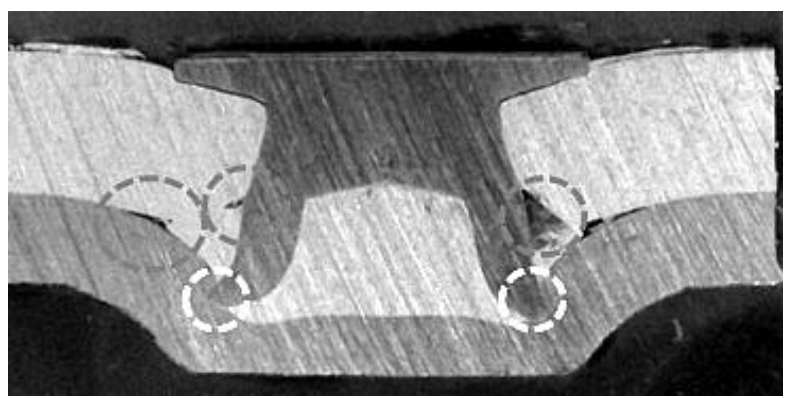

Fig. 10. Cross section of SPR joints.

As shown in Fig. 10, at both sides, cracks were observed inside dark/red circles. This was attributed to crack resulted from the lack of ductility of A356-T6. In addition, the light/yellow circle in Fig. 10 corresponds to the geometrical constraint of SPR.

2.2.2. The Tensile-Shear Strength of SPR Joints. As shown in Fig. 11, tensile-shear strength was $7.9 \mathrm{kN}$ for case 1 and $6.4 \mathrm{kN}$ for case 3 . The case 3 exhibited the lower tensile-shear strength than that of case 1. The height of lower mold was the same for both cases 1 and 3 but radiuses were 5 and $7 \mathrm{~mm}$, respectively. The tensile-shear strength of the SPR joints was approximately 2 times higher than that of the FSSW joints.

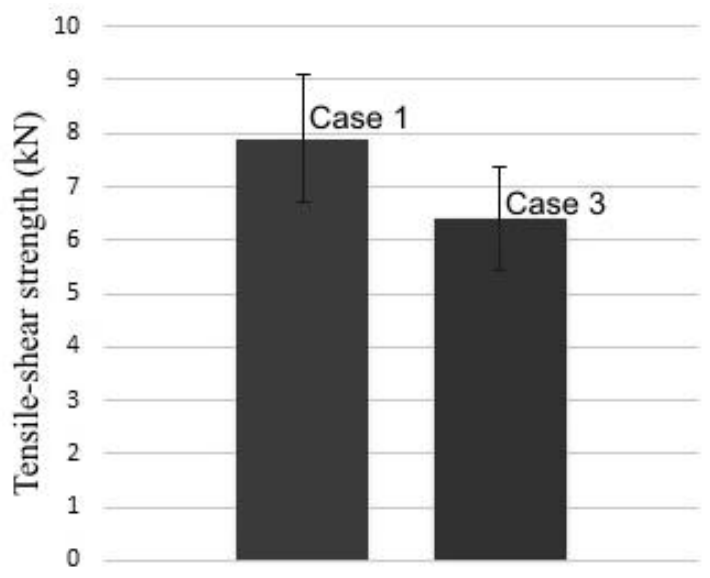

Fig. 11. Tensile-shear strength of SPR joints.

Conclusions. In this study, joining properties of dissimilar A356/SAPH440 lap joints by the FSSW and SPR were analyzed. The following conclusions were obtained:

1. Under all conditions of 300-500 rpm with $0.7-1.2 \mathrm{~mm}$ plunge depths, the interface of the FSSW joints was joined thoroughly. Notably, due to the fact that satisfactory plastic flow effect from the upper and lower materials, deeper than $0.7 \mathrm{~mm}$ of plunge depth led perfect lap-joints. However, when the tool plunge depth exceeds $1.0 \mathrm{~mm}$, the effective sheet thickness decreased and satisfied the required value of the resistance spot welding. 
2. The maximum tensile-shear strengths in the FSSW joints were approximately $3.5 \mathrm{kN}$ achieved at a rotation speed of $500 \mathrm{rpm}$ and plunge depth of $1.0 \mathrm{~mm}$. It was confirmed that the IMC layer of FSSW joints with $9.23 \mu \mathrm{m}$ was within permissible thickness $10 \mu \mathrm{m}$ of $\mathrm{Al}-\mathrm{Fe}$ joints.

3. In the case of the SPR, the maximum tensile-shear strengths in the SPR joints exhibited $7.9 \mathrm{kN}$ and was higher than that of the FSSW joints. However, crack formation happened in the joint at aluminum side due to the lack of ductility as characteristics of casting aluminum during the SPR process.

Acknowledgments. This work was supported by the Korea Science and Engineering Foundation (KOSEF) grant funded by the Korea Government (MOST) (No. 2016R1D1A3B03935978).

1. Y. S. Kim, "Future of the friction stir spot welding technology for non-ferrous metal," J. Weld. Join., 30, No. 3, 4-14 (2012).

2. S. H. Chowdhury, D. L. Chen, S. D. Bhole, et al., "Lap shear strength and fatigue behavior of friction stir spot welded dissimilar magnesium-to-aluminum joints with adhesive," Mater. Sci. Eng. A, 562, 53-60 (2013).

3. H. S. Bang, H. S. Bang, and G. H. Jeon, "Recent Studies on hybrid friction stir welding," J. Weld. Join., 28, No. 5, 35-37 (2010).

4. S. H. Kim, S. W. Kim, S. J. Park, and W. S. Chang, "Dissimilar friction spot joining: A5052-H32/A6022-T4," RIST J. R\&D, 21, No. 2, 153-159 (2007).

5. C. K. Chun, H. J. Kim, and W. S. Chang, "Friction stir spot joining on aluminum alloy for transportation," J. Weld. Join., 26, No. 6, 23-29 (2008).

6. Y. Abe, T. Kato, and K. Mori, "Self-piercing riveting of high tensile strength steel and aluminium alloy sheets using conventional rivet and die," J. Mater. Process. Technol., 209, 3914-3922 (2009).

7. Y. M. Yeon, C. Y. Lee, W. B. Lee, et al., "Spot friction stir welding and characteristics of joints in aluminium alloys," J. Weld. Join., 23, No. 3, 16-20 (2005).

8. E. H. Kim, K. J. Lee, and K. H. Song, "Evaluation of mechanical properties on friction stir lap jointed Al6061/HT590 alloys," J. Weld. Join., 33, No. 2, 8-13 (2015).

9. Y. Kim, K. Y. Park, and S. B. Kwak, "Mechanical fastening and joining technologies to using multi mixed materials of car body," J. Weld. Join., 33, No. 3, 12-18 (2015).

10. Y. H. Yin, N. Sun, T. H. North, and S. S. Hu, "Hook formation and mechanical properties in AZ31 friction stir spot welds," J. Mater. Process. Technol., 210, 2062-2070 (2010).

11. S. J. Lee, S. K. Lee, and N. I. Baik, "A study on the microstructure and hardness of Al-Si-Mg alloys upon heat treatments," J. Korean Soc. Heat Treat., 13, No. 2, 108-114 (2000).

12. D. Horstmann, "Formation and growth of iron-zinc alloy layers," in: Proc. of the 14th Int. Galvanizing Conf., Munish (1985), pp 18/1-18/5.

13. A. A. Hershman, "Alloy formation in hot dip galvanizing: a short review," in: Proc. of the 8th Int. Conf. on Hot Dip Galvanizing (Intergalva 67), London (1967), pp. 3-29.

14. Metals Handbook, 3rd edn, Japan Institute of Metal, Maruzen, Tokyo (1993).

15. K. S. Kim, Microstructures and Mechanical Properties of A356 Semisolid Metal Fabricated by Cooling Plate, Master Thesis, Gyeongsang National University (2000). 